\title{
Hypertension Clinic Service is a Good Opportunity for Tobacco Cessation in Bangladeshi Villagers
}

\author{
M Mostafa Zaman, Jasimuddin Ahmed, Sohel Reza Choudhury, Masud Ahmed, Tashfin Zissan \\ Ekhlaspur Center of Health (ECOH), Chandpur, Bangladesh
}

Key Words :
Tobacco,
Hypertension,
Primary health
care.

Abstract

Background: Tobacco use and hypertension are common and co-existent in Bangladeshi population. This study was done to assess whether a brief counseling by non-medical counselors during checkup visits for hypertension treatment can reduce tobacco use in Bangladeshi adults living in a village.

Methods: This study was done in a public health clinic located in a village of Bangladesh. Consecutive 259 hypertensive patients visiting this clinic for hypertension treatment were counseled for lifestyle modification at entry and four follow-up visits at an interval of four weeks. Tobacco users were counseled for five minutes to quit tobacco use at each visit as per a cessation booklet in Bangla. Data on tobacco use, smoking and smokeless, were recorded at all visits.

Results: Median age of the respondents was 55 years (in range, 18-85 years) and three-quarter of them were women. The prevalence of tobacco use in first visit was $40.5 \%$ which declined to $1.9 \%$ on their fifth visit. Major decline was observed due to smokeless tobacco quitting; its prevalence dropped from $33.2 \%$ to $0.4 \%$. However smoking was relatively resistant; it declined from $10.4 \%$ to $1.5 \%$ only.

Conclusion: Tobacco cessation by a simple counseling has been found to be very successful in this village level public health clinic of Bangladesh. This can be replicated in similar settings such as community clinics.

(Cardiovasc. j. 2016; 9(1): 19-22)

\section{Background:}

Tobacco, both smoking and smokeless products, consumption in Bangladeshi adults is very high. ${ }^{1}$ Fortunately smoking in women is very low. Various control measures-such as ad ban, smokefree campaign etc. are ongoing. Tobacco cessation initiatives are not visible in Bangladesh. Cessation programmes include two components: counseling and pharmacotherapy. ${ }^{2}$ In resource constraint settings like Bangladesh counseling is the first line of choice although a combination of counseling and pharmacotheraphy works better. Counseling delivered by physicians and other professionals significantly increases quit rates if the users are mentally prepared to quit. Even a brief 3-minute's counseling to urge smoker to quit results in smoking cessation rates of $5-10 \%{ }^{3}$ We have, anecdotally, observed that isolated cessation services can hardly attract tobacco users to come to clinics in absence of diseases, in Bangladesh. Cessation services can be integrated with services for other risk factors or diseases that require treatment.
Hypertension is a commonly prevalent risk factor, which itself is a disease that requires treatment. ${ }^{4}$ One in five Bangladeshi adults suffers from hypertension. ${ }^{1}$ Tobacco use and hypertension coexist as a result of their clustering. 1,5 Therefore hypertension clinic services should be used as an opportunity for tobacco cessation. ${ }^{6}$ This study was done to assess whether a brief counseling among hypertension clinic patients can facilitate quitting tobacco use in Bangladeshi adults living in a village.

\section{Methods:}

Ekhlaspur is one of the 68,000 villages of Bangladesh located in Matlab North sub-district of Chandpur district, about $60 \mathrm{~km}$ south-east of Dhaka city. A voluntary health centre, Ekhlaspur Centre of Health (ECOH) has been established in 1999 in Ekhlaspur. Ekhlaspur is an agricultural area having poor connectivity with towns, the background of which has been reported elsewhere. ${ }^{7}$ Salt and tobacco consumption is known to be high but alcohol is prohibited in this predominantly

Address for Correspondence: Prof. M Mostafa Zaman, Ekhlaspur Center of Health (ECOH), Chandpur, Bangladesh. Email: mmostafazaman@gmail.com 
Muslim village. Men consume both smoking and smokeless tobacco but women consume smokeless tobacco only. Smoking is hardly prevalent in women.

ECOH provides out-patient services to the people of Ekhlaspur. A hypertension clinic was established, in $\mathrm{ECOH}$, in October 2004 to screen hypertension once a week. The diagnosis of hypertension and initiation of treatment was done by a doctor. Subsequent follow up was done by two counselors. Counseling, measurement of blood glucose and antihypertensive medicines are provided to all patients free of charge. Counseling for about five minutes in each session was done using a small booklet on tobacco cessation. ${ }^{8}$ It was given to all tobacco users. Counseling included harmful effects of tobacco, its relation with complications of hypertension, and benefits of quitting tobacco. Classically it used 5A strategies (ask, advise, assess, assist, and arrange) in local language (Bangla). ${ }^{6,9}$

Between October 2004 and September 2014 a total of 259 patients registered in the hypertension clinic. They were routinely asked to come for follow up at four weeks interval. However, patients were advised to report back to the clinic any time before the schedule if felt necessary. As per protocol of the hypertension clinic, records of first five visits were mandatory. Information on blood pressure, salt and tobacco consumption were kept on paper based record-sheets.

Data of first five mandatory visits were entered in to EpiInfo ${ }^{\circledR}$ database version 7. Statistical analysis was based on these five visits of all patients rather than limiting it to tobacco users only. Mid points and dispersions were obtained for quantitative variables; and proportions with 95\% confidence intervals were obtained in case of categorical variables.

Because this analysis is based on routine clinic based services, ethical clearance was not sought but verbal consent of the patients was obtained.

\section{Results:}

The patients were aged from 18 to 85 years. They were followed-up for a median duration of about four months (112 days). Median age at the entry (first visit) was 55 years whereas it dropped down to 50 on the fifth visit. This may indicate that young people were more adherent to follow up visits. At the entry the median body weight was $49 \mathrm{Kg}$, which was increased to $50 \mathrm{Kg}$ on the fifth visit. Approximately three-quarter of them were women in all five visits.

Salt consumption on the table was very common at entry (73\%) but drastically reduced during follow up visits. Rate of uncontrolled blood pressure was also very high at entry (89\%) but reduced to $14 \%$ on fifth visit. Quitting of smokeless tobacco was quite prominent; it declined from $33.2 \%$ to $0.4 \%$ (Table I). All the smokeless tobacco products' (jarda, sada, gul, etc.) use declined uniformly. Compared to smokeless tobacco, smoking (cigarette and bidi) was a little resistant to change and the decline was from $10.4 \%$ to $1.5 \%$. Overall, the prevalence of tobacco use in any form was promising from $40.5 \%$ in first visit to $1.9 \%$ on fifth visit (Figure 1 ).

\section{Table-I}

Prevalence (95\% confidence interval) of variables of interest among patients of ECOH hypertension clinic $(n=259)$.

\begin{tabular}{lccccc}
\hline Variables & First visit & 2nd visit & 3rd visit & 4th visit & 5th visit \\
\hline Use salt on the table, \% & $73(68-79)$ & $43(35-51)$ & $28(21-38)$ & $15(9-25)$ & $13(6-24)$ \\
Uncontrolled BP, \% & $89(90-96)$ & $43(37-49)$ & $28(23-34)$ & $20(15-25)$ & $14(10-19)$ \\
Tobacco use, \% & & & & & \\
$\quad$ Smokeless & $33.2(27.5-39.3)$ & $10.8(7.3-15.2)$ & $5.0(2.7-8.4)$ & $2.7(1.1-5.5)$ & $0.4(0.0-2.1)$ \\
$\quad$ Smoking & $10.4(7.0-14.8)$ & $3.9(1.9-7.0)$ & $2.7(1.1-5.5)$ & $1.5(0.4-3.9)$ & $1.5(0.4-3.9)$ \\
\hline
\end{tabular}

BP indicates blood pressure 


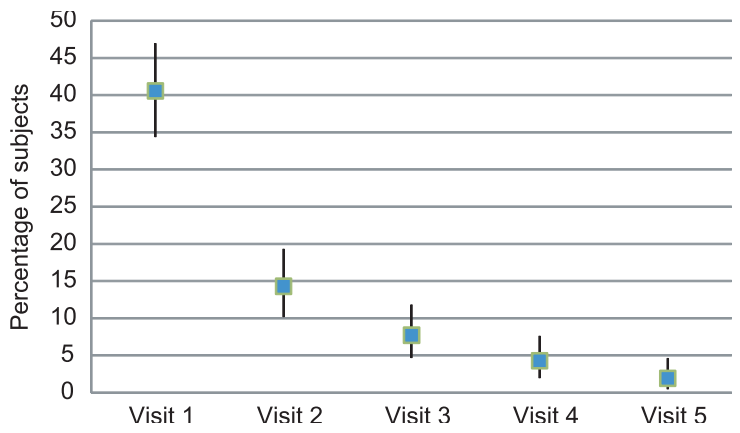

Fig.-1: Prevalence of tobacco use (in any form) in hypertensive patients at five visits (Error bars indicate $95 \%$ confidence intervals).

\section{Discussion:}

We could achieve a high quitting rate at the end of five counseling sessions in a median duration of about four months. However, major quit rate was seen after the first counseling session. Therefore the first contact in such a clinic based session should be considered as the golden opportunity. Along with a high quit rate of tobacco major benefit was obtained for dietary salt reduction and control of high blood pressure. This gives us a clue that establishment of 'risk factor' clinics instead of tobacco cessation clinics may bring more public health benefits.

There is hardly any cessation related data in Bangladesh. Global Adult Tobacco Survey (GATS), Bangladesh chapter report of 2009 reported that nearly half of the smokers received advice from health care providers to quit and half of smokers made attempts to quit during last 12 months. ${ }^{10}$ However International Tobacco Control (ITC) study 2009-2010 reported an attempt to quit rate of $21 \%$ and $4 \%$ of them were successful to maintain an abstinence of six months. ${ }^{11}$

One cessation clinic was set up in Bangabandhu Sheikh Mujib Medical University in 2011 with support from WHO. This stand alone cessation clinic could not attract tobacco users to seek counseling. Therefore its services were discontinued. Opportunistic cessation services integrated with other clinical services could be a viable option in Bangladesh. Mobile phone is very popular and widely available in Bangladesh. Therefore quit lines also could be tested as was found useful in some other countries. ${ }^{12}$ Tobacco cessation services integrated with oral health services were found to be successful in the United
States. ${ }^{13}$ India initiated a network of tobacco cessation clinics in 2002. Almost all of them were located in tertiary level health care facilities. Sixweek's cessation rate was relatively low (14\%) even with a combined effort of counseling and cessation drug therapies. ${ }^{14}$ This cessation rate is much lower than what we observed in our setting because we used an integrated approach of clinical service and cessation counseling together. ${ }^{15}$

We exploited a hypertension clinic in a rural area to test whether a simple counseling works for Bangladeshi tobacco users. Effectiveness of tobacco cessation counseling by health workers is not a novel approach but we report here for the first time a cessation experience among Bangladeshi villagers in a clinical setting. Bangladesh government has already established 18,000 community clinics as the lowest level primary health care setting. ${ }^{12}$ These are run by community health care providers (CHCPs) who have similar background of our counselors. Therefore community clinics have a huge potential of providing cessation services in Bangladesh.

In conclusion, hypertension screening is a good opportunity for tobacco cessation in community level health care settings in Bangladesh. This can be replicated in community clinics.

\section{Acknowledgements:}

Counselors of ECOH, Mr. Nazrul Islam, Mr. Sadequl Islam, Ms. Kazol Rakha and Ms. Nargis Akter have done the counseling and kept the records. One of us (MMZ) has donated the antihypertensive medicines. Mr.Abdus Sobhan, $\mathrm{Mr}$ Iqbal Hossain and Mr. Md Amanullah have mobilized the community on voluntary basis.

\section{Conflict of Interest - None.}

\section{References:}

11. Zaman MM, Bhuiyan MR, Huq SM, Rahman MM, Sinha DN, Fernando T. Dual use of tobacco among Bangladeshi men. Indian J Cancer 2014;51:46 9.

2. Kumar R, Vijayan VK. Smoking cessation programs and other preventive strategies for chronic obstructive pulmonary disease. J Assoc Physicians India 2012;58:53-6

3. Wilson DH, Wakefield MA, Steven ID, Rohrsheim RA, Esterman AJ, Graham NM. "Sick of Smoking": evaluation of a targeted minimal smoking cessation intervention in general practice. Med J Aust 1990 May $21 ; 152(10): 518-521$. 
4. Malik MA, Khandaker RK, Zaman MM, Choudhury SR (eds). National guidelines for management of hypertension in Bangladesh. Dhaka, WHO 2013. In: http://www.searo.who.int/bangladesh/en/ [3 January 2015].

5. Zaman MM, Rahman MM, Rahman MR, Bhuiyan MR, Karim MN, Chowdhury MA. Prevalence of risk factors for non-communicable diseases in Bangladesh: Results from STEPS survey 2010. Indian J Public Health 2016 Jan-Mar; 60(1):17-25.

6. Siddique MA, Sultan MAU, Haque S, Zaman MM, Ahmed CM, Rahim MA and Salman M. Clustering of metabolic factors among the patients with essential hypertension Bangladesh. Bangladesh Med Res Counc Bull 2008; 34: 71-75.

7. Zaman MM, Choudhury SR, Ahmed J, Hussain SMA, Sobhan SMM, Turin TC.Prevalence of stroke in a rural population of Bangladesh.Global Heart 2015.

8. Alliance for Community-based Tobacco Cessation.CANcerSUPpot (CANSUP) and Ekhlaspur Center of Health (ECOH).Muktobatashneen. In: http:/ /ntcc.gov.bd/uploads/books/Mukto-Batash-NeenACTC.pdf [3 January 2015].

9. Agency for Health Research and Quality. Treating tobacco use and dependence: 2008 update. http:// www.ahrq.gov/professionals/clinicians-providers/ guidelines - recommendations/tobacco/ index.html\#Clinic.

10. World Health Organization. Global Adult Tobacco Survey Bangladesh Report 2009, p75. Available at http:/ /www.searo.who.int/bangladesh/publications/ global_adult_tobaccot_2009.pdf?ua=1 [9 July 2016].

11. Abu S. Abdullah AS, Driezen P, Quah ACK, Nargis N, Fong GT. Predictors of smoking cessation behavioramong Bangladeshi adults: findings from ITC Bangladesh survey. Tobacco Induced Diseases 2015;13:23.

12. Hollis JF, McAfee TA, Fellows JL, Zbikowski SM, Stark $M$, Riedlinger $K$. The effectiveness and cost effectiveness of telephone counselling and the nicotine patch in a state tobacco quit line. Tobacco Control 2007;16:i53-i59.

13. Severson HH, Andrews JA, Lichtenstein E, Judith SG, Barkley MF. Using the hygiene visit to deliver a tobacco cessation programme:results of a randomized clinical trial. Journal of the American Dental Association 1998;129:993.

14. Varghese C, Kaur J, Desai NG, Murthy P, Malhotra S, Subbakrishna D K, Prasad VM, Munish VG. Initiating tobacco cessation services in India: challenges and opportunities. WHO South-East Asia Journal of Public Health 2012;1:159-168.

15. Thankappan KR. Tobacco cessation in India: A priority health intervention. Indian J Med Res 2014;139: 484-486.

16. Government of People's Republic of Bangladesh. Ministry of Health and Family Welfare.Revitalization of Community Health Care Initiative in Bangladesh (Community Clinic Project). In: http://www. communityclinic.gov.bd/about.php [3 January 2015]. 